\title{
Effects of strength and flexibility training on functional performance of healthy older people*
}

\author{
Efeitos do treinamento de força e flexibilidade no desempenho funcional de \\ idosos saudáveis*
}

Rafaella R. Locks ${ }^{1,2}$, Tatiana C. Costa ${ }^{3}$, Soraia Koppe ${ }^{4}$, Anelize M. Yamaguti ${ }^{5}$, Maurício C. Garcia ${ }^{6}$, Anna R. S. Gomes²,6

\begin{abstract}
Objective: To evaluate the effects of stretching and/or resistive exercise, followed by detraining, on the functional status of older people. Methods: Forty-five subjects were divided into four groups: control (CG; $n=13 ; 66 \pm 6$ years), stretching (SG; $n=10 ; 69 \pm 6$ years), resistive exercise (RG; $n=13 ; 69 \pm 5$ years), and resistive exercise and stretching (RSG; $n=9 ; 66 \pm 5$ years). The CG did not perform any exercise. The SG, RG, and RSG had warm-up sessions prior to performing lower-body exercises twice a week. The SG performed 4 repetitions of stretching. Resistive exercise was performed at a load of $65 \%$ of 10 repetitions maximum (RM) for five weeks, $70 \%$ for the next four weeks, and $75 \%$ for the last three weeks of the program. The RSG performed both exercises. Cardiorespiratory capacity was evaluated using the 6-minute walk test (6MWT) at baseline, at the six- and 12-week follow-ups, and after a six-week period of detraining. Lower limb muscle strength was assessed using the stand up from a chair and sit down test (SUCSD), and blood pressure was measured using a sphygmomanometer and a stethoscope. The results were analyzed using ANOVA ( $p \leq 0.05$ ). Results: Six weeks of training increased walking distance (6MWT) in the RG and decreased SUCSD time in the SG. However, detraining increased systolic blood pressure (SBP) in the RG compared to the SG. Diastolic blood pressure (DBP) decreased after six weeks in the RSG and 12 weeks in the SG. Conclusions: Six weeks of stretching or resistive training can improve the functional status of older people. Nevertheless, DBP decreased after six weeks with the combination of resistive exercise and stretching. Detraining increased SBP when resistive exercise alone was used.
\end{abstract}

Trial registration ACTRN12610000597099

Keywords: aging; muscle strength; physical therapy; blood pressure; movement; rehabilitation.

\section{Resumo}

Objetivo: Avaliar os efeitos do alongamento e/ou exercício resistido e destreinamento na performance funcional de idosos. Métodos: Quarenta e cinco sujeitos foram divididos em 4 grupos: controle (CG; $n=13 ; 66 \pm 6$ anos), alongamento (SG; $n=10 ; 69 \pm 6$ anos), resistido (RG; $n=13 ; 69 \pm 5$ anos), e resistido e alongamento (RSG; n=9; 66 \pm 5 anos). O CG não realizou exercícios. Os grupos SG, RG e RSG realizaram aquecimento seguido de exercícios para membros inferiores 2 vezes por semana. O SG realizou 4 repetições de alongamento. O exercício resistido foi realizado com carga de $65 \%$ de 10 repetições máximas (RM) durante 5 semanas, $70 \%$ nas 4 semanas seguintes e $75 \%$ nas últimas 3 semanas. O RSG realizou ambos os exercícios. Antes, após 6, 12 semanas, e após 6 semanas de destreinamento, a aptidão cardiorrespiratória foi avaliada usando o teste dos seis minutos de caminhada (6MWT), a força muscular dos membros inferiores pelo teste de sentar e levantar de uma cadeira (SUCSD) e pressão arterial sistêmica pelo esfigmomanômetro e estetoscópio. Os resultados foram comparados pela ANOVA $(p \leq 0,05)$. Resultados: Seis semanas de treinamento aumentaram a distância percorrida (6MWT) do RG e diminuíram o tempo do SUCSD no SG. No entanto, RG aumentou a pressão arterial sistólica (SBP) após o destreinamento comparada com o SG. A pressão arterial diastólica (DBP) diminuiu após 6 semanas para o RSG e 12 semanas para o SG. Conclusões: Seis semanas de alongamento ou treinamento resistido melhorou o desempenho funcional dos idosos. Porém, a DBP diminuiu após 6 semanas, com a associação do exercício resistido com o alongamento. Já o destreinamento, aumentou a SBP em idosos que treinaram exercício resistido isolado. Registro de ensaio clínico ACTRN12610000597099.

Palavras-chave: idoso; força muscular; fisioterapia; pressão arterial; movimento; reabilitação.

Received: 08/17/2010 - Revised: 04/11/2011 - Accepted: 09/06/2011

${ }_{1}^{1}$ Physical Therapist, Hospital Regional Infantil Waldemar Monastier, Campo Largo, PR, Brazil

${ }^{2}$ Postgraduate Physical Education Program, Universidade Federal do Paraná (UFPR), Curitiba, PR, Brazil

${ }^{3}$ Physical Therapist, Hospital Regional da Lapa, and Department of Mechanical Engineering, UFPR, Curitiba, PR, Brazil

${ }^{4}$ Physical Therapist, Internship Program of Hospital de Clínicas, UFPR, Curitiba, PR, Brazil

${ }^{5}$ Physical Therapist, Secretaria da Saúde do Estado do Paraná, Paranaguá, PR, Brazil

${ }^{6}$ Undergraduate Physical Therapy Program, UFPR, Matinhos, PR, Brazil

Correspondence to: Anna Raquel Silveira Gomes, Rua Jaguariaiva 512, CEP 83260-000, Matinhos, PR, Brazil, e-mail: annaraquelsg@gmail.com

*Part of this study was presented as an abstract at the 19 IAGG World Congress of Gerontology and Geriatrics and XVIII Congresso Brasileiro de Fisioterapia, 2009. 


\section{Introduction $: \therefore$.}

There are a number of structural and functional changes that occur in humans with the aging process. These changes result in a decline in physical activity and eventually a reduction in functional capacity. Among the age-related changes, the ones that contribute the most to loss of functional autonomy are reductions in muscle strength, flexibility, and cardiorespiratory capacity ${ }^{1,2}$.

Muscle stretching combined with resistive exercises performed three times a week has been described as the best intervention to decrease or prevent loss of muscle mass, strength, mobility, balance, and flexibility in older people ${ }^{3-7}$. These exercises have also been shown to improve the functional capacity of older adults even when performed in isolation ${ }^{8}$. Other beneficial effects of resistive training are reduced blood pressure at rest ${ }^{9,10}$, improved cardiorespiratory capacity ${ }^{11,12}$, and reduced body fat ${ }^{13}$. The results of a long-term follow-up study suggested that older people who continued to exercise after a year had significantly greater improvement in strength immediately after the intervention, compared to those who discontinued the resistance program $^{7}$. However, it still has not been determined whether resistive exercise combined with stretching exercise can lead to greater improvement in functional and cardiorespiratory capacity in older people compared to resistive or stretching exercise alone.

The optimal frequency and intensity of resistive training remain undefined, as do the potential benefits of combining resistive and stretching exercises to maintain functional gains in older people after detraining. Therefore, the aim of this study was to evaluate the effects of progressive resistive exercise, stretching or a combination of both on the functional status of healthy older people after interventions and after detraining.

\section{Methods $: \because$.}

\section{Study design and setting}

This study was an experimental controlled clinical trial with convenience distribution. Ethical approval was obtained from the Human Research Ethics Committee of Universidade Federal do Paraná (UFPR), Curitiba, PR, Brazil (Reference No.: CAAE 0021.0.091.000-08). Written informed consent was obtained from all participants. The study was developed at the UFPR, Coast Sector and Physical Therapy's Clinic School in Matinhos, PR, Brazil.

\section{Recruitment}

Participants were recruited at meetings organized by the Municipal Health Office of Matinhos, PR, Brazil. Participants were invited to attend meetings through local radio and local community groups.

\section{Eligibility criteria}

The study included men and women over 60 years of age in a stable condition who were Brazilian National Health System (SUS) users; who had medical clearance to perform the proposed exercises; and who had not participated in any regular physical activity over the last six weeks. The exclusion criteria were: joint injury or surgery; cardiac disease; cancer; neuropathies; use of prostheses; systolic blood pressure (SBP) over $120 \mathrm{mmHg}$ and diastolic blood pressure (DBP) over $80 \mathrm{mmHg}$ at rest; no medical clearance to participate; participation in another structured exercise program more than once a week during the last six weeks; contraindications for exercise in accordance with the Brazilian Hypertension Guidelines (Diretrizes Brasileiras de Hipertensão) ${ }^{14}$; severe functional limitations or significant cognitive impairment that could affect adherence to the program.

\section{Group assignment}

The participants elected one of the four treatment groups to which they would be allocated: control (CG), stretching (SG), resistive (RG), and resistive and stretching (RSG). The initial sample consisted of 83 older individuals but, over the course of the study, 38 participants were excluded for the following reasons: dyspnea during assessment ( 1 from the $\mathrm{CG}$ ), performing other physical activities while taking part in the study (3 from the $C G, 2$ from the $R G$ ), presence of painful varicose veins in lower limbs ( 2 from the RSG), a fractured humerus as the result of a fall during the training period ( 1 from the RSG), resting DBP of $120 \mathrm{mmHg}$ in the first assessment (1 from the RSG), attendance of less than $60 \%$ of the exercise sessions (2 from the SG, 4 from the RG, 2 from the RSG $)^{14}$ and failure to attend one or more of the assessments (18 from the CG, 2 from the RG), as shown in Figure 1.

Forty-five healthy older individuals ( 25 female; 20 male; $67.5 \pm 2$ years old) completed the protocol: the CG ( $66 \pm 6$ years old; $\mathrm{n}=13$ ) attended a one-hour seminar on healthy living every four weeks and did not perform any physical or therapeutic exercise over the trial period; the RG $(69 \pm 5$ years old; $n=13)$ performed resistive exercises; the SG $(69 \pm 6$ years old; $\mathrm{n}=10)$ performed stretching exercises; the RSG $(66 \pm 5$ years old; $n=9)$ performed resistive exercises followed immediately by stretching. 


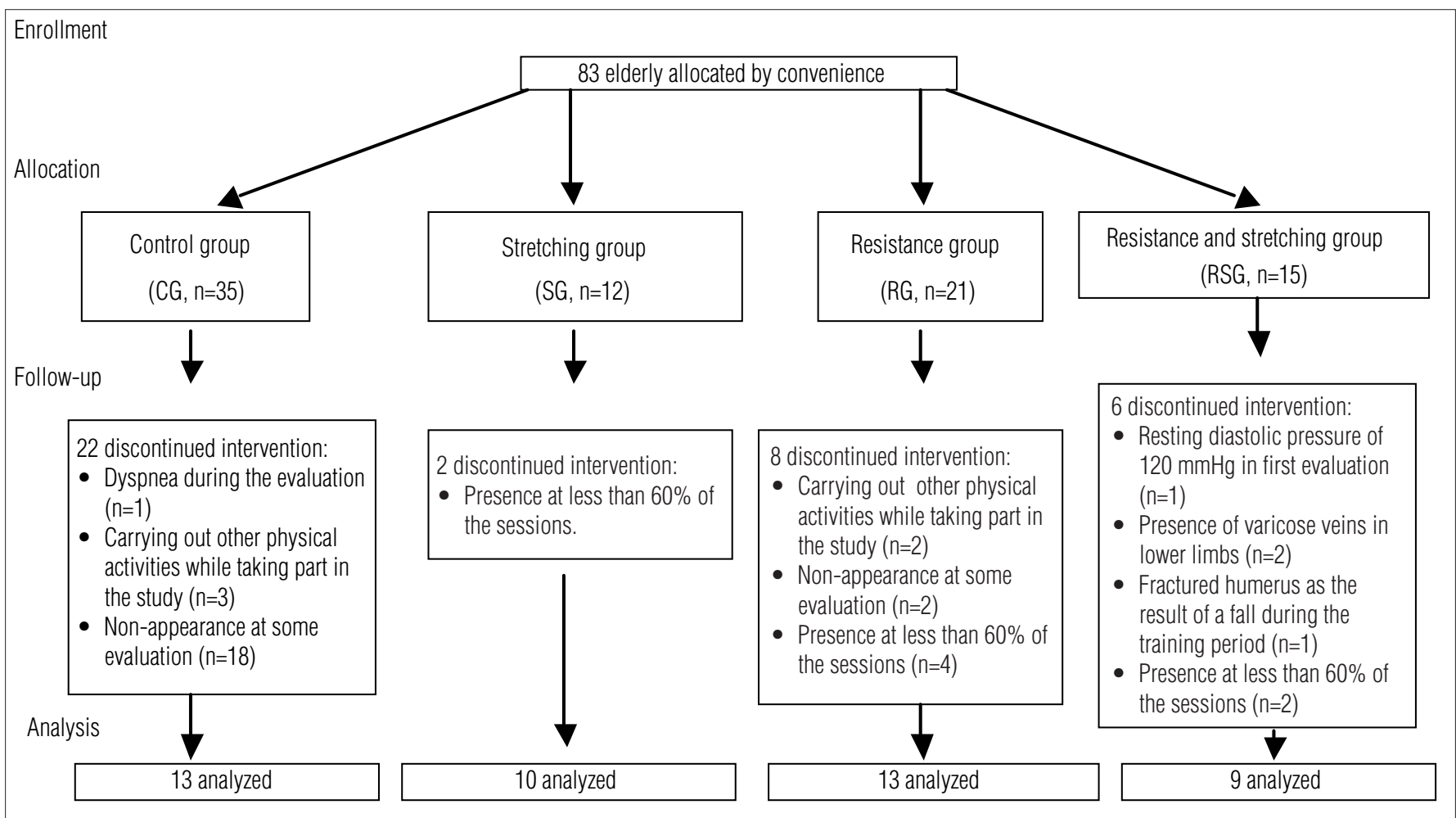

Figure 1. Study design. Flow of participants throughout the study.

Exercises were performed under the supervision of a physical therapist and three physical therapy students at UFPR. The exercise sessions were conducted twice a week at regular times for a total of 24 sessions of approximately 55 minutes each. Participants attending at least $60 \%$ of the sessions were considered to be active in the study ${ }^{15}$.

The anthropometric variables evaluated were height and weight ${ }^{16,17}$. Blood pressure was measured in accordance with the $6^{\text {th }}$ Brazilian Hypertension Guidelines (Diretrizes Brasileiras de Hipertensão) ${ }^{14}$ by the stethoscopic method, using a sphygmomanometer (Solidor) and stethoscope (Premium) prior to the beginning of each testing session. An appropriate-sized cuff (cuff bladder encircling at least 80 percent of the arm) was used to ensure accuracy. SBP was the point at which the first of two or more sounds was heard (phase 1 Korotkoff), and DBP was the point before the disappearance of sounds (phase V Korotkoff) ${ }^{14}$. All assessments were conducted in the afternoon.

\section{6-Minute Walk Test (6MWT)}

Participants were instructed to walk for 6 minutes around a marked 20-meter track (9 meters in length $\mathrm{x} 1$ meter in width). Participants were encouraged to walk continuously at a comfortable pace but with the aim to cover as much ground as possible in 6 minutes. The distance covered was measured in meters with the use of a tape measure ${ }^{17}$.

\section{Lower limb function}

Lower limb strength was evaluated by the stand up from a chair and sit down test (SUCSD). Participants were instructed to stand up from a chair and sit down five times as quickly as possible. The time taken to perform this test was recorded using a digital stopwatch (Herweg) $)^{18}$. The test was performed three times, and the results were expressed as the mean between trials.

\section{Experimental procedure}

\section{Warm-up Protocol}

A 10-minute warm-up session was performed at the start of each session. The warm-up consisted of walking and recreational activities to bring variety to the exercise sessions ${ }^{19}$.

\section{Resistive Exercise Protocol}

The ten-repetition maximum (10-RM) technique was used to determine the ideal training weight for each participant. This test was performed using shin-pads. The 
10-RM technique evaluates lifting capacity with respect to the maximum weight that can be moved 10 times with little action of the muscle groups that are not the primary motors of the movement under evaluation ${ }^{20}$.

The progressive resistive program consisted of 3 sets of 8 repetitions performed twice a week for 12 consecutive weeks. Strengthening exercises were performed bilaterally using weighted shin-pads, and the muscle groups targeted were: knee extensors (seated position) and knee flexors (standing upright); hip extensors (standing upright) and flexors (lying down on back); and the hip abductors and adductors (standing upright). The plantar flexors were tested and trained in the upright standing position using body weight ${ }^{9,20}$. Training intensity was set at $65 \%$ of $10-\mathrm{RM}$ for the first 5 weeks, $70 \%$ of 10-RM for the next 4 weeks, and $75 \%$ of $10-\mathrm{RM}$ for the last 3 weeks. Adjustment of the 10-RM was determined immediately before the third and eighth weeks of training ${ }^{21}$.

\section{Stretching procedure}

The stretching exercises consisted of a series of four repetitions of active static stretching, each lasting $1 \mathrm{~min}$ and respecting the tension limit of each individual, with 1 min of relaxation between repetitions. The exercises were performed with both limbs twice a week for 12 consecutive weeks. The type of stretching, duration, and number of repetitions were adapted from Chan, Hong and Robinson ${ }^{22}$, Feland et al. ${ }^{3}$, and Taylor et al. ${ }^{23}$ respectively. The following lower limb muscle groups were stretched: knee extensors and ankle dorsiflexors in the upright standing position ${ }^{24}$; knee flexors and ankle plantar flexors using a non-elastic band in the supine position with extended knee and ankle dorsiflexion of the stretched limb, according to the modified methods of Chan, Hong and Robinson ${ }^{22}$ and Feland et al. ${ }^{3}$. During knee flexor stretching, the hip and knees of the contralateral limb were flexed.

\section{Statistical analysis}

The sample calculation demonstrated the need to include 16 subjects per group to reach a statistical power of $80 \%$ and detect a $20 \%$ increase in strength ${ }^{25}$. The data collected were presented as means \pm standard deviation (Tables 1 to 3 ). After that, we calculated the percentage of gain between the first and second, second and third, and third and fourth assessments. Subsequently, the data were submitted to repeated measures analysis of variance (ANOVA) followed by Fisher's post hoc test to compare the groups over the four assessments. The significance level was set at $\mathrm{p} \leq 0.05$.

\section{Results : :}

\section{MWT}

No differences were found between groups in the 6MWT. However, the within-group analysis showed a greater percentage gain in the RG after six weeks of training compared to the percentage gain after 12 weeks of training $(15.53 \pm 11.40 \%$, $481 \pm 56 \mathrm{~m}$ vs. $418 \pm 53 \mathrm{~m}$ compared to $2.70 \pm 4.79 \%, 481 \pm 56 \mathrm{~m}$ vs. 469 \pm 63 m; $p=0.006$; Table 1).

\section{Lower limb strength}

Similarly to the 6MWT, no differences in lower limb strength were found among the groups as assessed by the stand up from a chair and sit down test (SUCSD). The within-group comparisons showed that, in the SG, the percentage gain was greater after six weeks of training $(14 \pm 9.22 \%, 10.1 \pm 1.93 \mathrm{~s}$ vs. $8.7 \pm 2.04 \mathrm{~s})$ than after 12 weeks ( $1.84 \pm 16.12 \%, 8.7 \pm 2.04$ s vs. $8.6 \pm 1.06 \mathrm{~s}$; $\mathrm{p}=0.008$; ANOVA). In the RSG, the SUCSD time decreased only after 12 weeks of training $(7.41 \pm 14.99 \%, 8.66 \pm 1.33 \mathrm{~s}$ vs. $8 \pm 1.22 \mathrm{~s})$ compared to the detraining period $(-19.91 \pm 12.97 \%, 8.00 \pm 1.22 \mathrm{~s}$ vs. $9.51 \pm 1.23 \mathrm{~s} ; \mathrm{p}=0.00002$; ANOVA). Likewise, the CG had a shorter SUCSD time after 12 weeks of training $(6.64 \pm 11.21 \%, 8.8 \pm 1.34 \mathrm{~s}$ vs. $8.07 \pm 1.59 \mathrm{~s})$ than after the detraining period $(-4.5 \pm 9.68 \%, 8.07 \pm 1.59 \mathrm{~s}$ vs. $8.38 \pm 1.1 \mathrm{~s}$; $\mathrm{p}=0.03$; ANOVA). The results are shown in Table 2 .

\section{Blood pressure}

After detraining, the RG showed a significantly greater increase in SBP compared to the SG $(-6.95 \pm 12.12 \%, 137 \pm 17 \mathrm{mmHg}$ vs. $146 \pm 21 \mathrm{mmHg}$ compared to $1.10 \pm 11.18 \% \quad 137 \pm 22 \mathrm{mmHg}$ vs. $134 \pm 16 \mathrm{mmHg}$; $=0.03$; ANOVA). In the DBP analysis, after six weeks of training the RSG had lower values than the SG $(4.55 \pm 7.92 \%, 79 \pm 8 \mathrm{mmHg}$ vs $75 \pm 7 \mathrm{mmHg}$ compared to $-3.81 \pm 11.63 \%, 83 \pm 11 \mathrm{mmHg}$ vs $86 \pm 14 \mathrm{mmHg}$, $\mathrm{p}=0.003$; ANOVA) and CG $(-5.78 \pm 11 \%, 80 \pm 13 \mathrm{mmHg}$ vs $84 \pm 11 \mathrm{mmHg}, \mathrm{p}=0.003$; ANOVA).. In the SG, DBP decreased only after 12 weeks compared to the RG $(6.81 \pm 16.62 \%, 86 \pm 14 \mathrm{mmHg}$ vs. $79 \pm 13 \mathrm{mmHg}$ compared to $3.89 \pm 9.17 \%, 81 \pm 8 \mathrm{mmHg}$ vs. $85 \pm 11 \mathrm{mmHg}$; $=0.004$; ANOVA) and the RSG (-5.45 $\pm 8.80,75 \pm 7 \mathrm{mmHg}$ vs. $79 \pm 8 \mathrm{mmHg}$; $\mathrm{p}=0.003$; ANOVA). The results are shown in Table 3.

\section{Discussion $: \because 8$}

The results of this study suggest that after six weeks of training, the twice-weekly resistive or stretching exercise promoted an increase in the cardiorespiratory capacity and lower limb strength of older individuals. However, changes in DBP were 
also identified, with a greater reduction in the RSG, which combined resistive and stretching exercise. Nevertheless, detraining caused an increase in SBP in the participants of the RG, which performed only resistive exercise. To date, no other studies have evaluated subjects after a short training period (six weeks), during detraining, and at a low frequency of training, i.e. twice a week.

Alves et al. ${ }^{26}$ showed improved performance in the 6MWT and in the SUCSD in older women after a 12-week water aerobics program performed twice a week. The program included stretching, aerobic exercises, resistive training of the upper and lower limbs, abdominal exercises, and relaxation. The present study shows that the same can be achieved with a six-week program of twice-weekly stretching or resistive exercise and that stretching or resistive exercise can enhance cardiorespiratory capacity and lower limb strength in older individuals.

A study found that an active stretching program, performed twice a week for 4 weeks, was effective in increasing knee flexor and extensor isokinetic torque and functional mobility in older women ${ }^{27}$. In the present study, the SUCSD test was used to evaluate lower limb strength, and the results showed that performance time was shorter after six weeks of stretching. This outcome is in line with Batista et al. ${ }^{27}$, showing that stretching exercise alone can also increase muscle strength. Accordingly, it could be hypothesized that the gain in the 6MWT found in the RG might not be attributed to muscle strength because no effect was observed in lower limb strength.

The RSG and CG reduced SUCSD time during detraining compared to the third assessment. Therefore, the change in muscle strength of the RSG cannot be ascribed to the effect of exercise as this increase was also seen in the CG. However, the combination of resistive exercise and stretching of the RSG caused a decrease in DBP after six weeks while the SG only showed a reduction after 12 weeks of training. Additionally, the RG had an increase in SBP after the detraining period.

It could be assumed that the gain in cardiorespiratory capacity (6MWT) in the RG contributed to the maintenance of the SBP during the training program but it was not sufficient to maintain it after detraining. It has been reported that short-term strength training improves cardiovascular function in healthy middle-aged and older adults but it can be lost after four weeks of detraining ${ }^{28}$.

A reduction in blood pressure can be one of the effects of resistive training ${ }^{10,29}$. Reduced DBP was found in the RSG and SG after six and 12 weeks of training, respectively. The decrease found in the RSG cannot be credited to the cardiorespiratory (6MWT) and muscle strength (SUCSD test) gains because no effect was found. However, the reduction in DBP of the SG could be ascribed to the muscle strength gain
Table 1. Walking distance in meters (m) by groups in the six-minute walk test (6MWT) before (pre-training), after six (post-6) and 12 (post-12) weeks of training, and after six weeks of detraining (post-detraining).

\begin{tabular}{lcllc}
\hline 6MWT (m) & Pre-training & Post- 6 & Post-12 & Post-detraining \\
\hline CG & $400 \pm 79$ & $418 \pm 69$ & $449 \pm 81$ & $447 \pm 125$ \\
\hline SG & $389 \pm 62$ & $444 \pm 78$ & $446 \pm 80$ & $451 \pm 194$ \\
\hline RG & $418 \pm 53$ & $481 \pm 56^{*}$ & $469 \pm 63$ & $492 \pm 107$ \\
\hline RSG & $421 \pm 52$ & $446 \pm 50$ & $454 \pm 63$ & $426 \pm 43$ \\
\hline
\end{tabular}

Values are mean $\pm S D$. $C G=$ control group; $S G=$ stretching group; $R G=$ resistive exercise group RSG=resistive exercise and stretching group. ${ }^{\star} \mathrm{p}=0.006$ when compared to post- 12 .

Table 2. Time of performance in seconds (s) in the SUCSD of the groups before (pre-training), after six (post-6) and 12 (post-12) weeks of training and after six weeks of detraining (post-detraining).

\begin{tabular}{lrccc}
\hline SUCSD (s) & Pre-training & Post-6 & Post-12 & Post-detraining \\
\hline CG & $9.61 \pm 2.33$ & $8.8 \pm 1.34$ & $8.07 \pm 1.59^{*}$ & $8.38 \pm 1.1$ \\
\hline SG & $10.1 \pm 1.93$ & $8.7 \pm 2.04^{*}$ & $8.6 \pm 1.06$ & $9.33 \pm 1.96$ \\
\hline RG & $10.05 \pm 1.67$ & $8.71 \pm 1.5$ & $8.2 \pm 1.41$ & $8.53 \pm 1.49$ \\
\hline RSG & $10.33 \pm 1.86$ & $8.66 \pm 1.33$ & $8 \pm 1.22^{*}$ & $9.51 \pm 1.23$ \\
\hline
\end{tabular}

Values are mean $\pm S D$. $C G=$ control group; $S G=$ stretching group; $R G=$ resistive exercise group: $\mathrm{RSG}=$ resistive exercises and stretching group. ${ }^{+} p=0.03$ in comparison to post-detraining (ANOVA). ${ }^{*} \mathrm{p}=0.008$ when compared to post-12 (ANOVA). ${ }^{*} \mathrm{p}=0.00002$ when compared to post-detraining (ANOVA)

Table 3. Systolic blood pressure (SBP) and diastolic blood pressure (DBP) of groups before (pre-training), after six (post-6) and 12 (post-12) weeks of training, and after six weeks of detraining (post-detraining).

\begin{tabular}{lllll}
\hline & Pre-training & Post-6 & Post-12 & Post-detraining \\
\hline SBP $(\mathrm{mmHg})$ & & & & \\
\hline CG & $132 \pm 18$ & $131 \pm 17$ & $140 \pm 22$ & $141 \pm 23$ \\
\hline SG & $140 \pm 27$ & $137 \pm 23$ & $137 \pm 22$ & $134 \pm 16$ \\
\hline RG & $141 \pm 13$ & $135 \pm 15$ & $137 \pm 17$ & $146 \pm 21^{*}$ \\
\hline RSG & $129 \pm 8$ & $125 \pm 9$ & $128 \pm 17$ & $130 \pm 16$ \\
\hline DBP $(\mathrm{mmHg})$ & & & & \\
\hline CG & $80 \pm 13$ & $84 \pm 11$ & $82 \pm 13$ & $82 \pm 8$ \\
\hline SG & $83 \pm 11$ & $86 \pm 14$ & $79 \pm 13^{+}$ & $82 \pm 11$ \\
\hline RG & $81 \pm 6$ & $81 \pm 8$ & $85 \pm 11$ & $88 \pm 16$ \\
\hline RSG & $79 \pm 8$ & $75 \pm 77^{\S}$ & $79 \pm 8$ & $78 \pm 9$ \\
\hline
\end{tabular}

Values are mean $\pm S D$. $C G=$ control group; $S G=$ stretching group; $R G=$ resistive exercise group; $R S G=r e s i s t i v e$ exercise and stretching group. ${ }^{*} p=0.03$ compared to the $S G$ (ANOVA). ${ }^{+} p<0.004$ when compared to the RG and RSG (ANOVA). ${ }^{8} p=0.003$ compared to the $\mathrm{CG}$ and $\mathrm{SG}$.

(SUCSD test). It has been described that the level of muscle strength has an inverse relationship to the blood pressure response to exercise ${ }^{10}$. These outcomes suggest that stretching had an important role in the reduction of DBP because resistive exercise alone was only sufficient to maintain blood pressure during six weeks of training, but the combination with stretching reduced DBP.

Studies on the effects of stretching exercises on the cardiovascular system are limited. However, one study recently found an increase in SBP after acute passive stretching 
sessions $^{30}$. In contrast, another study reported lower DBP when the stretching program was performed regularly ${ }^{31}$. The authors discussed this outcome for the use of relaxation procedures based primarily on muscle stretching exercises to decrease muscle tension and cardiovascular rates. Thus, the current findings provide indications that the autonomic nervous system may be involved in the effects of stretching exercises when regularly performed.

The literature often describes the effects of stretching exercise programs on flexibility, range of motion, and mobility but not on the cardiovascular system. Moreover, some studies have used stretching as a control, neglecting its cardiovascular effect ${ }^{32,33}$. Therefore, the outcomes of this study indicate that stretching should not be ignored in the investigations about the cardiovascular system.

The limitations of this study include convenience sample distribution and small sample size due to drop outs, which may have reduced the power of inference and generalization of the data. Factors that could have assisted in explaining the findings of this study but were not assessed include: peak torque, lower limb isometric muscle strength, and hemodynamic assessments. The outcomes used in this study, including the 6MWT and the SUCSD, were selected for use in this study because they have been shown to be valid and reliable in assessing older adults ${ }^{34-36}$.

The conclusion of this study is that progressive resistive or stretching training was effective in improving the functional performance of older people. Other benefits to exercising as identified in this study included a decrease in DBP in the RSG detected earlier (six weeks) than in the RG (12 weeks). Future research is required to determine the exact mechanisms responsible for the improvement in blood pressure after resistive and/or stretching exercises such as the increase in blood pressure observed after detraining when resistance exercises were performed alone.

The present study has made a substantial contribution to the prescription of exercises by physical therapists to older people. It highlights the improvements that can be obtained when a twice-weekly stretching or resistive training program is performed, alone or combined, for six weeks.

\section{References: ::}

1. Mattos M, Farinatti P. Influência do treinamento aeróbio com intensidade e volumes reduzidos na autonomia e aptidão físico-funcional de mulheres idosas. Rev Port Ciênc Desporto. 2007;7(1):100-8.

2. Holland GJ, Tanaka K, Shigematsu R, Nakagaichi M. Flexibility and physical functions of older adults: a review. J Aging Phys Act. 2002;10:169-206.

3. Feland JB, Myrer JW, Schulthies SS, Fellingham GW, Measom GW. The effect of duration of stretching of the hamstring muscle group for increasing range of motion in people age 65 years or older. Phys Ther. 2001;81(5):1110-7.

4. Gajdosik RL, Vander Linden DW, McNair PJ, Williams AK, Riggin TJ. Effects of an eight-week stretching program on the passive-elastic properties and function of the calf muscles of older women. Clin Biomech (Bristol, Avon). 2005;20(9):973-83.

5. Kamel HK. Sarcopenia and aging. Nutr Rev. 2003;61(5 Pt 1):157-67.

6. Thompson LV. Skeletal muscle adaptations with age, inactivity, and therapeutic exercise. J Orthop Sports Phys Ther. 2002;32(2):44-57.

7. Bird M, Hill KD, Ball M, Hetherington S, Williams AD. The long-term benefits of a multicomponent exercise intervention to balance and mobility in healthy older adults. Arch Gerontol Geriatr. 2011;52(2):211-6

8. Bird ML, Hill K, Ball M, Williams AD. Effects of resistance- and flexibility-exercise interventions on balance and related measures in older adults. J Aging Phys Act. 2009;17(4):444-54.

9. Terra DF, Mota MR, Rabelo HT, Bezerra LMA, Lima RM, Ribeiro AG, et al. Reduction of arterial pressure and double product at rest after resistance exercise training in elderly hypertensive women. Arq Bras Cardiol. 2008;91(5):274-9

10. Umpierre D, Stein R. Efeitos hemodinâmicos e vasculares do treinamento resistido: implicações na doença cardiovascular. Arq Bras Cardiol. 2007;89(4):256-62.

11. Ades PA, Ballor DL, Ashikaga T, Utton JL, Nair KS. Weight training improves walking endurance in healthy elderly persons. Ann Intern Med. 1996;124(6):568-72.

12. Vincent KR, Braith RW, Feldman RA, Kallas HE, Lowenthal DT. Improved cardiorespiratory endurance following 6 months of resistance exercise in elderly men and women. Arch Intern Med. 2002;162(6):673-8.

13. Tsutsumi T, Don BM, Zaichkowsky LD, Delizonna LL. Physical fitness and psychological benefits of strength training in community dwelling older adults. Appl Human Sci. 1997;16(6):257-66.
14. Nobre F. VI Diretrizes brasileiras de hipertensão. Rev Bras Hipertens. 2010;17(1):5-6.

15. Glazer KM, Emery CF, Frid DJ, Banyasz RE. Psychological predictors of adherence and outcomes among patients in cardiac rehabilitation. J Cardiopulm Rehabil. 2002;22(1):40-6

16. Brasil. Ministério da Saúde. Secretaria de Atenção à Saúde. Departamento de Atenção Básica. Antropometria: como pesar e medir. Brasília: MS; 2004

17. Krause MP, Buzzachera CF, Hallage T, Pulner SB, Silva SG. Influência do nível de atividade física sobre a aptidão cardiorrespiratória em mulheres idosas. Rev Bras Med Esporte. 2007;13(2):97-102.

18. Bastone AdeC, Jacob Filho W. Effect of an exercise program on functional performance of institutionalized elderly. J Rehabil Res Dev. 2004;41(5):659-68.

19. Agre JC, Pierce LE, Raab DM, McAdams M, Smith EL. Light resistance and stretching exercise in elderly women: effect upon strength. Arch Phys Med Rehabil. 1988;69(4):273-6.

20. Navega MT, Aveiro MC, Oishi J. A influência de um programa de atividade física na qualidade de vida de mulheres com osteoporose. Fisioter Mov. 2006;19(4):25-32.

21. Charette SL, McEvoy L, Pyka G, Snow-Harter C, Guido D, Wiswell RA, et al. Muscle hypertrophy response to resistance training in older women. J Appl Physiol. 1991;70(5):1912-6.

22. Chan SP, Hong Y, Robinson PD. Flexibility and passive resistance of the hamstrings of young adults using two different static stretching protocols. Scand J Med Sci Sports. 2001;11(2):81-6

23. Taylor DC, Dalton JDJr, Seaber AV, Garrett WEJr. Viscoelastic of muscle-tendon units. The biomechanical effects of stretching. Am J Sports Med. 1990;18(3):300-9.

24. Kisner C, Colby LA. Therapeutic exercise: foundations and techniques. $5^{\text {th }}$ Ed. Philadelphia: FA Davis Company; 2007

25. Luiz RR, Magnanini MMF. A lógica da determinação do tamanho da amostra em investigações epidemiológicas. Cad Saúde Colet (Rio J). 2000;8(2):9-28.

26. Alves RV, Mota J, Costa MC, Alves JGB. Aptidão física relacionada à saúde de idosos: influência da hidroginástica. Rev Bras Med Esporte. 2004;10(1):31-7.

27. Batista LH, Vilar AC, de Almeida Ferreira JJ, Rebelatto JR, Salvini TF. Active stretching improves flexibility, joint torque, and functional mobility in older women. Am J Phys Med Rehabil. 2009;88(10):815-22. 
28. Lovell DI, Cuneo R, Gass GC. Strength training improves submaximum cardiovascular performance in older men. J Geriatr Phys Ther. 2009;32(3):117-24.

29. Pollock ML, Franklin BA, Balady GJ, Chaitman BL, Fleg JL, Fletcher B, et al. AHA Science Advisory. Resistance exercise in individuals with and without cardiovascular disease: benefits, rationale, safety, and prescription: An advisory from the Committee on Exercise, Rehabilitation, and Prevention, Council on Clinical Cardiology, American Heart Association; Position paper endorsed by the American College of Sports Medicine. Circulation. 2000;101(7):828-33

30. Farinatti PTV, Soares PPS, Monteiro WD, Duarte AFA, Castro LAV. Cardiovascular responses to passive static flexibility exercises are influenced by the stretched muscle mass and the Valsalva maneuver. Clinics. 2011;66(3):459-64.

31. Carlson CR, Collins FL Jr, Nitz AJ, Sturgis ET, Rogers JL. Muscle stretching as an alternative relaxation training procedure. J Behav Ther Exp Psychiatry. 1990;21(1):29-38.
32. Cortez-Cooper MY, Anton MM, Devan AE, Neidre DB, Cook JN, Tanaka H. The effects of strength training on central arterial compliance in middle-aged and older adults. Eur J Cardiovasc Prev Rehabil. 2008;15(2):149-55.

33. Anton MM, Cortez-Cooper MY, DeVan AE, Neidre DB, Cook JN, Tanaka H. Resistance training increases basal limb blood flow and vascular conductance in aging humans. J Appl Physiol. 2006;101(5):1351-5.

34. ATS Committee on Proficiency Standards for Clinical Pulmonary Function Laboratories. ATS statement: guidelines for the six-minute walk test. Am J Respir Crit Care Med. 2002;166(1):111-7.

35. Fahlman MM, McNevin N, Boardley D, Morgan A, Topp R. Effects of resistance training on functional ability in elderly individuals. Am J Health Promot. 2011;25(4):237-43.

36. Chyu MC, James CR, Sawyer SF, Brismée JM, Xu KT, Poklikuha G, et al. Effects of tai chi exercise on posturography, gait, physical function and quality of life in postmenopausal women with osteopaenia: a randomized clinical study. Clin Rehabil. 2010;24(12):1080-90. 